\title{
A girl with labium majus swelling
}

\author{
Federica Pederiva
}

Received: 31 August 2013 / Accepted: 17 September 2013/Published online: 29 September 2013

(C) Springer-Verlag Berlin Heidelberg 2013

\begin{abstract}
Asymmetric vulva swelling during prepubertal period is related to a variety of inflammatory and neoplastic lesions. An 11-year-old girl with childhood asymmetric labium majus enlargement is presented.
\end{abstract}

Keywords CALME $\cdot$ Vulva $\cdot$ Soft tissue mass

An 11-year-old girl presented with a 3-month history of painless swelling of the right labium majus. There was no history of genitalia trauma or of abdominal surgery. Physical examination revealed a soft, ill-defined enlargement of the right labium majus with normal overlying skin (Fig. 1). Neither cystic nor solid lesions were palpated. The inguinal and genital examination was otherwise normal. She was prepubertal in Tanner stage II. Ultrasound showed increased labial soft tissue on the affected side with a similar echogenicity to the contralateral side. The unilateral labium majus swelling without inflammatory and neoplastic features was diagnosed as childhood asymmetric labium majus enlargement (CALME).

CALME is a nonneoplastic expansion of normal vulvar soft tissue in response to prepubertal hormonal stimulation recalling unilateral breast enlargement. The prognosis is good, and biopsy or surgical treatment is not necessary $[1,2]$.

The pediatricians should keep in mind CALME and not to erroneously misdiagnose these cases as neoplastic lesions.

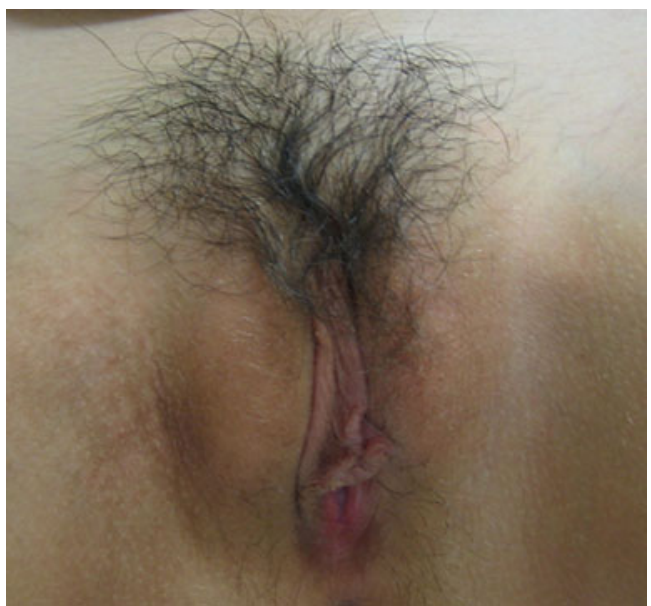

Fig. 1 Enlargement of the right labium majus

Conflict of interest There is no financial assistance or any potential conflict of interest, real or perceived.

\section{References}

1. Soyer T, Hancerliogullari O, Pelin Cil A, Evliyaoglu O, Cakmak M (2009) Childhood asymmetric labium majus enlargement: is a conservative approach available? J Pediatr Adolesc Gynecol 22:e9-e11

2. Vargas SO, Kozakewich HP, Boyd TK, Ecklund K, Fishman SJ, Laufer MR, Perez-Atayde AR (2005) Childhood asymmetric labium majus enlargement: mimicking a neoplasm. Am J Surg Pathol 29: $1007-1016$
F. Pederiva $(\bowtie)$

Pediatric Surgery, Institute for Maternal and Child Health - IRCCS

"Burlo Garofolo", Via dell'Istria 65/1, 34137 Trieste, Italy

e-mail: federica_pederiva@yahoo.it 